\title{
Correction to: Effect of Electroacupuncture at Siguan Acupoints on Expression of BDNF and TrkB Proteins in the Hippocampus of Post-Stroke Depression Rats
}

\author{
Zhen Kang $^{1} \cdot$ Haimin $\mathrm{Ye}^{1} \cdot$ Tao Chen $^{2} \cdot$ Peng Zhang ${ }^{1}$
}

Published online: 29 June 2021

○) Springer Science+Business Media, LLC, part of Springer Nature 2021

Correction to: Journal of Molecular Neuroscience (2021)
https://doi.org/10.1007/s12031-021-01844-4

In the published article "Effect of Electroacupuncture at Siguan Acupoints on Expression of BDNF and TrkB Proteins in the Hippocampus of Post-Stroke Depression Rats," affiliation should be interchanged as the below order:

${ }^{1}$ The Second Affiliated Hospital of Hunan University of Chinese Medicine, No. 233 Cai E North Road, Changsha 410005, Hunan Province, China

${ }^{2}$ Hunan University of Traditional Chinese Medicine, Changsha 410208, China

The original article has been corrected.
Publisher's Note Springer Nature remains neutral with regard to jurisdictional claims in published maps and institutional affiliations.

The original article can be found online at https://doi.org/10.1007/ s12031-021-01844-4.

Peng Zhang

35401725@qq.com

Zhen Kang

1320207894@qq.com

Haimin Ye

56842028@qq.com

Tao Chen

545677619@qq.com

1 The Second Affiliated Hospital of Hunan University of Chinese Medicine, No. 233 Cai E North Road, Changsha 410005, Hunan Province, China

2 Hunan University of Traditional Chinese Medicine, Changsha 410208, China 